\title{
INITIAL CHARACTERIZATION OF A BGO-PHOTODIODE DETECTOR FOR HIGH RESOLUTION POSITRON EMISSION TOMOGRAPHY
}

\author{
Stephen E. Derenzo
}

\author{
Donner Laboratory \\ Lawrence Berkeley Laboratory \\ University of California \\ Berkeley, California 94720
}

November 1983

\section{DISCLAIMER}

\begin{abstract}
This report was prepared as an account of work sponsored by an agency of the United States Government. Neither the United States Government nor any agency thereof, nor any of their employees, makes any warranty, express or implied, or assumes any legal liability or responsibility for the accuracy, completeness, or use:ulness of any information, appat it: lis, product, or process disclosed, or represents that its use would not infringe privately owned rights. Reference herein to any specific commercial product, process, or service by trade neme, trademark, manufacturer, or otherwise does not necessarily constitute or imply its endorsement, recommendation, or favoring by the United States Government or any agency thereof. The views and opinions of authors expressed herein do not necessarily state or reflect those of the United States Government or any agency thereol.
\end{abstract}

This work was supported by the U.S. Department of Energy under Contract No. DE-AC03-765F00098 and N.I.H. Grnt P0I HL25840. 


\author{
Stephen E. Derenzo \\ Donner Laboratory and Lawrence Berkeley Laboratory
}

Berkeley, CA 94720

\section{Abstruct}

Spatial resolution in positron enission tonography is currently imited by the resolution of the detectors. This work presents the initial characterization of detector design using sinall bisinuth germanate (BGO) crystals individually coupled to silicon photodrodes (SPDs) for crystal ident if ication, and coupled in groups to phot ot ubes (PMT a) for coincidence timing. A $3 \mathrm{~mm} \times 3 \mathrm{~mm} \times 3 \mathrm{~mm}$ BEO $\mathrm{cr}$-stal coupled only to a SPO can achieve a $511 \mathrm{keV}$ photopeak resolution of B.77 FHHM at $-150^{\circ} \mathrm{C}$. using a puise peaking $t$ ime of 10 us. When two $3 \mathrm{~mm} \times 3 \mathrm{~mm} \times 15 \mathrm{~mm}$ BGO crystals dre coupled individually to SPOS and also coupled to a common $14 \mathrm{~mm}$ diam PMT, the SFOs detect the $511 \mathrm{keV}$ photopeak with a resolution of $30 \%+6 H M$ at $-76^{\circ} \mathrm{C}$. In coincifence with an opposing $3 \mathrm{~mm}$ wide $B G O$ crystal, the SPOS are able to identify the crystal of interaztion with good signal-to-noise rat 10, and the dete:ior pair resolution is $2 \mathrm{~nm}$ FHHM.

\section{Introduction}

In positron emission tomography of the brain, a spatial resolut ion of $2 \mathrm{~mm}$ FHHM is needed to measure the dynamics of blood flow in the cerebral arteries and the uptake and clearance of labeled tracers in

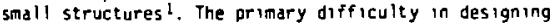
a positron tomograph with this spatial resolution lies not in the range of the positrons 2,3 , nor the deviations from $180^{\circ}$ emission", nor the detection proper. ties of small BGO crystalss, but in the size of ava:lable PMTs. Approaches to achieve a spatial resolution finer than the size of the PHTs include the use of lightpipes 6,7 . partial coupling of PMTs to various faces of a close-packed array of smaller crystals?, 8 . one dimensional light-praportion position logic $9-13^{\circ}$, selective splitting of light mong several PMTs so that the crystal producing the light may be identified 14,15 , the use of pulse shape discrimination for different scintillator materials on the same PMT16,17, and grid wires for localized gating of electrons from the photocathode to the first dynode ${ }^{28-21}$.

This paper presents the initid characterization of a detector design using smali bismutín germanate (BGO) crystals individually coupled to silicon photodrodes (SPOS) for crystal identification, and coupled in groups to phototubes (PMTs) for coincidence timing3,22. Our imite Carlo computer code 23 calculated that the largest fraction of light is collected when the SPD and PMT are coupled to the full ared of orthogonal faces of the crystal (Fagure 1).

In additicn, this paper describes the use of forward Compton scatters to enhance detection eff 1 crency without sacrificing spatial resolution, and the advantages of position-sensitive SPDs to medsure the depth-of-interaction in the crystal.

-Supported by 0.0.E. Contract DE-ACO3-76SF00098 and M.I.H. Grant POl H.25840.

\section{Properties of silicon photodiodes}

Table $\downarrow$ lists our measurements of some of the properties of four comercial SPOs. At $-100^{\circ} \mathrm{C}$, and at reverse bias voltages be low breakdom, dark current is be low 1 pA for all oiodes insted.

For an atrupt dicte (i.e. having an abrupt change in donor/acceptor concent ration between $P-I-N$ layers). the depletion depth $D$; in inf) is given by ${ }^{24}$

$$
0=0.5 \sqrt{a V_{e}}
$$

where $p$ is the resistivity of the silic in ohm-cm, $v_{e}=V_{i}+V_{b}$ is the effective diode pote lal, $V_{1}$ is the built-in potential and $V_{b}$ is the ext.sinal bias. The capacitance C (in of) is given by

$$
\mathrm{C}=106 \mathrm{~A} / \mathrm{O}
$$

where $A$ is the area $i n \mathrm{~mm}^{2}$. 0 is limited by the physical thickness of the silicon wafer.

We measured the capicitance of the four SFDs at a temperature of $-1000 \mathrm{C}$ for approximately 25 voltages from zero to the breakdown voltage. Equations and 2 did not describe these data, but an excellent . t was obtained in all cases when Equation 1 was replated by the enpirical expression

$$
0=0.5 \sqrt{a V_{e} /\left(I+V_{e} / V_{d}\right)}
$$

where $V_{d}$ is a voltage that corresponds to the as,mptot ic upper limit of $D$.

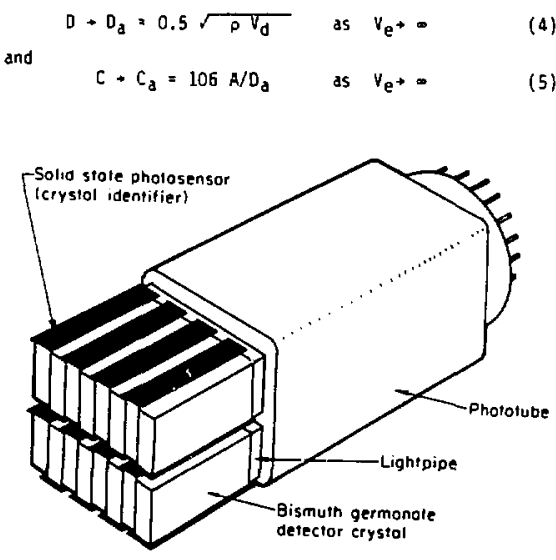

xwo212-4ste

Figure 1: Schematic of multiple-crystal array where the energy deposited in each crystal is measured by individudily coupled silicon photodiodes (SPDs) and the coincident $t$ ime information is provided by a common phototube (PMT). 
Table 1. Characteristics of four comercial silicon photadiodes

\begin{tabular}{|c|c|c|c|c|}
\hline Hanuf acturer & Hamanat Su & Hananat su & Mamanatsu & $\begin{array}{c}\text { Applied Solar } \\
\text { Energya }\end{array}$ \\
\hline Model & $51722-01$ & $51722 x$ & $51863 x$ & $\mathrm{H} 101$ \\
\hline Sensitive area & $\begin{array}{c}4 \mathrm{~mm} \mathrm{di} a \mathrm{~m} \\
\left(12.6 \mathrm{~mm}^{2}\right\}\end{array}$ & $\begin{array}{l}5 \text { m diam } \\
(19.6 \mathrm{~mm} 2)\end{array}$ & $10 \underset{\left(100 \mathrm{~mm}^{2}\right)}{\min }$ & $\begin{array}{c}2.0 \mathrm{~mm} \text { diam } \\
\left(3.1 \mathrm{~mm}^{2}\right)\end{array}$ \\
\hline $\begin{array}{l}\text { Breakdown vo Tt age } \\
\text { Capacit ance near breakdown } \\
\text { Corresponding depletion depth }\end{array}$ & $\begin{array}{r}180 \mathrm{~V} \\
11.8 \mathrm{pF} \\
113 \mathrm{~m} \mathrm{n}\end{array}$ & $\begin{array}{l}200 \mathrm{~V} \\
7.2 \mathrm{of} \\
2 \mathrm{Ag} \mathrm{m}\end{array}$ & $\begin{array}{r}80 \mathrm{~V} \\
35 \mathrm{pf} \\
303 \mathrm{~m}\end{array}$ & $\begin{array}{r}50 \mathrm{~V} \\
3.7 \mathrm{dF} \\
89 \mathrm{~mm}\end{array}$ \\
\hline $\begin{aligned} \text { Capacitance at } V_{b}=0 V \\
V_{b}=1 V \\
V_{b}=2 V \\
V_{b}=5 V \\
V_{b}=10 V \\
V_{b}=20 V \\
V_{b}=50 V \\
V_{b}=100 V \\
V_{b}=200 V\end{aligned}$ & $\begin{array}{ll}55 & \mathrm{pF} \\
24 & \mathrm{pF} \\
20 & \mathrm{pF} \\
15 & \mathrm{oF} \\
14 & \mathrm{oF} \\
13 & \mathrm{pF} \\
12 & \mathrm{oF} \\
12 & \mathrm{oF} \\
& \end{array}$ & $\begin{array}{l}32 \mathrm{pF} \\
3 \mathrm{or} \\
23 \mathrm{pF} \\
29 \mathrm{pF} \\
21 \mathrm{pF} \\
16 \mathrm{pF} \\
11 \mathrm{pF} \\
8.5 \mathrm{pF} \\
7.2 \mathrm{pF}\end{array}$ & $\begin{array}{r}309 \mathrm{pF} \\
173 \mathrm{pF} \\
140 \mathrm{pF} \\
103 \mathrm{pF} \\
80 \mathrm{pF} \\
61 \mathrm{pF} \\
43 \mathrm{pF} \\
\end{array}$ & $\begin{array}{l}23 \mathrm{pF} \\
15 \mathrm{pF} \\
9.1 \mathrm{pF} \\
6.0 \mathrm{pF} \\
4.7 \mathrm{pF} \\
4.1 \mathrm{pF} \\
3.7 \mathrm{pF} \\
\\
\cdots\end{array}$ \\
\hline $\begin{array}{l}\text { Results of fit by eqn (3): } \\
\text { Resise ivity o (ohm-cm) } \\
\text { Built-in reverse bias } v_{i} \\
V_{d} \\
V_{e} \text { - - capacitance } c_{d} \\
y_{e} \text { - - depletion depth } o_{d}\end{array}$ & $\begin{array}{r}14,000 \\
-0.18 v \\
3.7 v \\
11.8 E^{E} \\
113 \text { t" }\end{array}$ & $\begin{array}{r}4.300 \\
-0.23 \mathrm{~V} \\
11 \mathrm{t} \mathrm{V} \\
5.8 \mathrm{pF} \\
354 \mathrm{im}\end{array}$ & $\begin{array}{r}7,700 \\
.76 \mathrm{~V} \\
93 \mathrm{~V} \\
25 \mathrm{pF} \\
423 \mathrm{~min}\end{array}$ & $\begin{array}{r}4.400 \\
-0.20 \mathrm{~V} \\
9.4 \mathrm{~V} \\
3.4 \mathrm{pF} \\
96 \mathrm{um}\end{array}$ \\
\hline
\end{tabular}

The best fit paraneters $o, V_{i}$, and $V_{d}$ are given in Table 1. The $51722 X$ and $S 1863 X$ were fabricated from 500 un silicon wafers and exhibit the lowest capacitance per unit ared $\left(0.35 \mathrm{pF} / \mathrm{mm}^{2}\right)$. However, the capacitance could be further reduced through the use of higher resistivity silicon and doping techniques that do not reduce the resistivity of the l-layer.

The seaicanductor $\mathrm{Hgl}_{2}$ is also being developed as a scintillation photodetector 25,26 , but is not yet comme: : 1 ally avariable.

\section{Characteristics of the BGO-photodiode detector}

3.1 Photopedk amplitudes and resolutions vs garme ray energy

As described in Reference (27), a selected $3 \mathrm{~mm}$ $3 \pi \times 3 \times$ in BGO c-ystal (Harshaw Chemical Co.. Solon. Ohiol was coupled to a Hamandsu 51722.01 SPD and coated with dry MgO reflector. Below $-50^{\circ} \mathrm{C}$. Oark current is $10 \mathrm{w}$ and does not significant ly contribute to amplifier noise. Using a $4393 \mathrm{FET}$, a SPD reverse bias of $10 \mathrm{~V}$ a temperature of $-150^{\circ} \mathrm{C}$, and a pulse peaking time of $0.5 \mathrm{ks}$, the aplifier noise $15560 \mathrm{e}^{-}$ FuHA. The noise is reduced by longer peaking times. and is $300 e^{-}$Fin do $r \neq 10$ ps. The capacitive lodd of the charqe anplifier (Figure 2) includes $15 \mathrm{pF}$ from the FET and 12 of from the SPD.

The best photopeak resolution was observed at d temperature of $-150^{\circ} \mathrm{C}$ and peak ing time of $10 \mathrm{us}$. Under these conditions, the photopeak anplitude and resolution were medsired for several ganma ray ener. gies \{Table 2\}. A typical 22 $\mathrm{Na}$ spectrum (Figure 3) shows the $511 \mathrm{keV}$ and $1275 \mathrm{keV}$ photopeaixs with Fwin = 8.77 and $5.4 x$, respect ively.
Applied Solar Energy Corpuration, City of Industry, CA

\section{2 intrinsic luminosity and light collection from 860}

To detemine the intrinsic luminosity of $B G 0$, we used a $10 \mathrm{~mm} \times 10 \mathrm{~mm} \times 3 \mathrm{~mm}$ deep $B(\mathrm{~h}$ ) crystal with one $10 \mathrm{~mm} \times 10 \mathrm{~mm}$ face polished and the other 5 faces roughened and painted black. In such a crystal, only photons within a $+45^{\circ}$ cone can escape total internal reflection in the $B G 0(n=2.15)$ and enter the PMT winJow $(n=1.52)$.

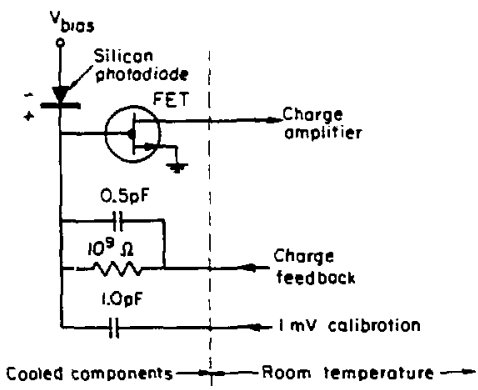

r.6.33+354s

Figure 2: Circuit didgram of cooled components of charge anplifier. Subsequent pulse shaping consisted of equal $R C$ integration and different iation. 


\begin{tabular}{|c|c|c|c|c|}
\hline \multicolumn{4}{|c|}{$\begin{array}{l}\text { Table 2. Photopeak response of a } 3 \times 3 \times 3 \\
\text { crystal and a } 51722=01 \text { SPO at }-150^{\circ} \mathrm{C} \\
\tau=10 \text { us, and } 10 \mathrm{~V} \text { reverse bias }\end{array}$} & \multirow{2}{*}{$\begin{array}{l}m^{3} 360 \\
\text { anplitude } \\
\text { per s } \\
\left(\mathrm{e}^{-/ \mathrm{ke}}\right)\end{array}$} \\
\hline Source & ${ }_{\text {(kev) }}^{E_{y}}$ & $\begin{array}{l}\text { bhot opeak } \\
\text { amplitude } \\
\left(e^{-}\right)\end{array}$ & $\begin{array}{l}\text { photopeak } \\
\text { FWHM }\end{array}$ & \\
\hline${ }^{3}{ }^{3} \mathrm{Ba}$ & 80 & 870 & $46 \%$ & 10.9 \\
\hline${ }^{57} \mathrm{CO}$ & 122 & 1.290 & $38 x$ & 10.5 \\
\hline $133 \mathrm{Ba}$ & 356 & 4.080 & $13 x$ & 11.5 \\
\hline $22 \mathrm{Na}$ & 511 & 5,990 & 8.78 & 11.7 \\
\hline $137 \mathrm{Cs}$ & 662 & 7,800 & $7.2 \pi$ & 11.8 \\
\hline $22 \mathrm{Na}$ & 1275 & 15,100 & $5.4 \pi$ & 11.8 \\
\hline${ }^{50} \mathrm{CO}$ & 1332 & 15,800 & $5.3 x$ & 11.9 \\
\hline
\end{tabular}

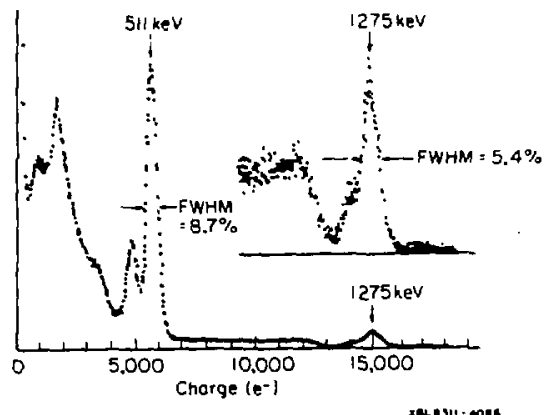

Figure 3: Pulse height spectrum from 22 Ha taken with a $3 \min \times 3 \times 3 \mathrm{~mm}$ BGO Crystal and a 51722-01 SPD. using a peaking time of $10 \mu s$ and at a tempersture of $-150^{\circ} \mathrm{C}$.

Our Monte Carlo computer code calculated that 12.78 of the scintillation photons will exit the black BGO crystal, assuming a scattering length of $1 \mathrm{~m}$, an absorption length of $1 \mathrm{~m}$, and a diffuse reflectivity of 3x. Suppressing either the scattering or absorption changed the collection fraction by less than 0.26 . This insensitivity is oue to the short paths (avg $3.5 \mathrm{~mm}$ ) that the photons trave? in the crystal before they are eithar collected or absorbed. Changing the assumed reflectivity to $0 x$ and $6 \%$ resulted in collection fractions of $12.0 \%$ and 13.3\%. respectively.

At a temperature of $-100^{\circ} \mathrm{C}$, the black $B G 0$ crystal has a $662 \mathrm{kel}$ photopeak amplitude of $2800 \mathrm{e}^{-}$using a Handant Su S1863X SPD. Assuming a quant um efficiency of $65 x^{20}$. We conclude that $2,800 /(0.13 \times 0.65)=33.000$ photons are produced in the $B G 0$ crystal, or 50 photons per key. Since each photon has approximately $2.6 \mathrm{eV}$, this corresponds to an intrinsic energy efficiency of $50 \times 2.6$ eV per keV $=13 x$.
At a temperature of $420^{\circ} \mathrm{C}$ a polished $3 \times 3$ × $3 \mathrm{~mm}$ deep $B G O$ crystal coated with $\mathrm{MgO}$ reflector has a 662 kev photopeak amplitude of $3,200 \mathrm{e}^{-}$using a $51722 \mathrm{SPD}$. At $-100^{\circ} \mathrm{C}$ the amplitude is $8,000 \mathrm{e}^{-}$, Wich is a 2.5-fold increase. At $+20^{\circ} \mathrm{C}$ the intrinsic Iuminosity of BGO is thus $33,000 / 2.5=13,200$ photons ar 20 photons per keV $(20 \times 2.6$ eV per keV $=5 \times$ energy efficiency).

We have used a PRT to measure the light output of a good-quality Nal(T) crystal relative to a ulack MaI(TI) Crystal, as well as the BGO crystals discussed above. The white NaI(TI) crystal is $30 \mathrm{~mm}$ dian $x 30 \mathrm{~mm}$ deep and has a 662 kev photopeak resolution of $8.5 \%$ FWH. Its output is $2.5 x$ larger than $12 \mathrm{~mm} \times 12 \mathrm{mon} x$ 3 mint deep Nal(TI) crystal painted black, which has calculated collection fraction of $18 x$. The collection fraction for the wite Nal(T) crystal is thus $18 x \times$ $2.5=45 \%$. Its output is also 8 times larger than BGO crystal having a similar collection fraction. Since the bialkali photocatinode used has about $30 \%$ more quant um efficiency for $\mathrm{Nal}(T))(420 \mathrm{~nm})$ than for 860 (480 $\mathrm{mm}$ ), the luminosity rat to between the two materials is about 6 . Thus the intrinsic luminosity of $\mathrm{kal}(\mathrm{TI})$ at $20^{\circ} \mathrm{C}$ is about 120 photons per $\mathrm{keV}$ and the intrinsic efficiency is about $120 \times 3.0 \mathrm{eV}$ per keV : 36x. The energy efficiency for light exit ing the crystal is $36 \% \times 45 \%=16 \%$, in reasonable agreement with the 137 measured by Van Sciver 29,30 .

\section{Crystal ident if ication with 5 blicon photodiodes}

To demonstrate the use of SPOS to identify ind vidud 860 crystals, used the test set-up shown in Figure 4 . The upper PMT was coupled to a single $3 \mathrm{~mm} x$ $10 \mathrm{~mm} \times 30 \mathrm{~mm}$ deep BGO crystal. The lower PMT was coupled to two $15 \mathrm{~mm} \times 3 \mathrm{~mm} \times 3 \mathrm{~mm}$ wide $860 \mathrm{crystals.}$ Each of the lower crystals was also coupled to an 51722-01 5PD. The separation between opposing detectars was about $25 \mathrm{~cm}$, and a $22 \mathrm{Na}$ line source was placed between them. A wire mesh at cathode potential was placed between the crystais and the front face of the lower PMT to prevent couping of PMT puises to the very sensitive charge anplifiers. If this precaution Is not taken, the charge amplifiers detect art if act pulses mose amplitudes depend on the PMT voltage. The lower PMT, 8GO crystals, SPDS, and associated charge amplifier components (figure 2 ) were cooled to $-76^{\circ} \mathrm{C}$ with an 8 liter, ttree-stage refrigeration unit (FTS Systens, Inc.. Stione Ridge, NY).

Figure 5 shows the pulse height spectra from $5 P 0$ $B$ taken with a gated pulse height analyzer. The gate pulse was derived from a coincidence between the two phototubes using thresholds of $400 \mathrm{keV}$. When the $22 \mathrm{Na}$ source is directly between the upper BGO crystal and crystal A (source position $-1.5 \mathrm{~mm}$ ), the pulse height spectrum seen on SPO $B$ consists primarily of noise pulses (Figure 5d). When the source is directly between the upper crystal and crysta? $B$ (source posi. tion + $1.5 \mathrm{~mm}$ ), the pulse height spectrum consists primarlly of 511 key photopeak pulses (Figure $5 \mathrm{C}$ ). The photodeak resolution is $30 \mathrm{z}$ Fulm, poorer than the resolution given in Table 2, due to the higher temperature, light losses in the longer crystals, and the sharing of light with the PMT.

Figure 6 shows the coincident response of opposing $3 \mathrm{~mm}$ wde $260 \mathrm{crystals}$ as the $22 \mathrm{Ha}$ source was moved in $0.25 \mathrm{~mm}$ steps alang d line between them. The curve marked phototube is the coincident response of the two PMTs. Since the lower PMT cannot dist inguish between the two BEO crystals, the response is relati. ely broad with a FWH of $2.9 \mathrm{~mm}$. The curve marked phocodiode $A$ is the coincident response of the two

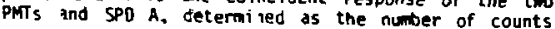




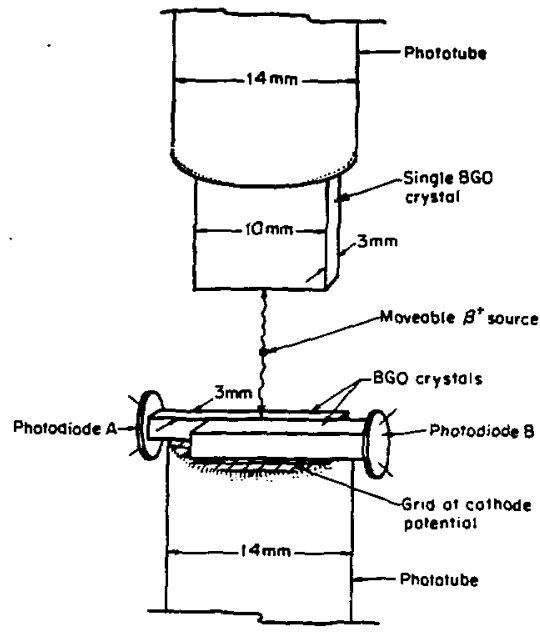

ML1 $1310 \cdot 4070$

Figure 1: Sketch of experimental set-up where two crystals are coupled to a common oMT and coupled individualty to SPDS.

above $310 \mathrm{keV}$ in the SPD A pulse height spectrum as seen by the gated pulse height andyzer. The curve marked photodiode $B$ is the coincident response of the two PMT s and SPD B. The curve marked photodiode $A+B$ is the sun of the photodiode $A$ and photodiode $B$ curves and is equal to $90 x$ of the phototube curve. The $10 x$ difference is primarily due to Compton scattering in one of the laver crystals followed by photoeiectric absorption in the other crystal.

\section{Tomoaraph Design Factors}

\subsection{Adyant ages of pos it ion sensitive photodetectors}

There are three primary sdvantages to the use of depth-of-interaction information: (1) Pardllax error due to perietration in the crystals from of $f-a x i s$ sources can be essentially eliminated. (2) By rotating all crystals in the sane direction (Figure 7 ), it is possiole to use the penetration effect to achieve essentially cont inuous sampling without detector notion. (3) Time-of-flight tomographs suffer from d loss in timing resalution because the scintillation photons travel more slowly than the incident annihilation photons. As a result, the thing resolution is significantly poorer for long crystals than for shorter crystals, resulting in a trade-off between tireing resolution and detection efficiency31. By knowing the depth of interaction, the timing resolution can be improved for long, efficient crystals. (a) Source position $=-1.5 \mathrm{~mm}$
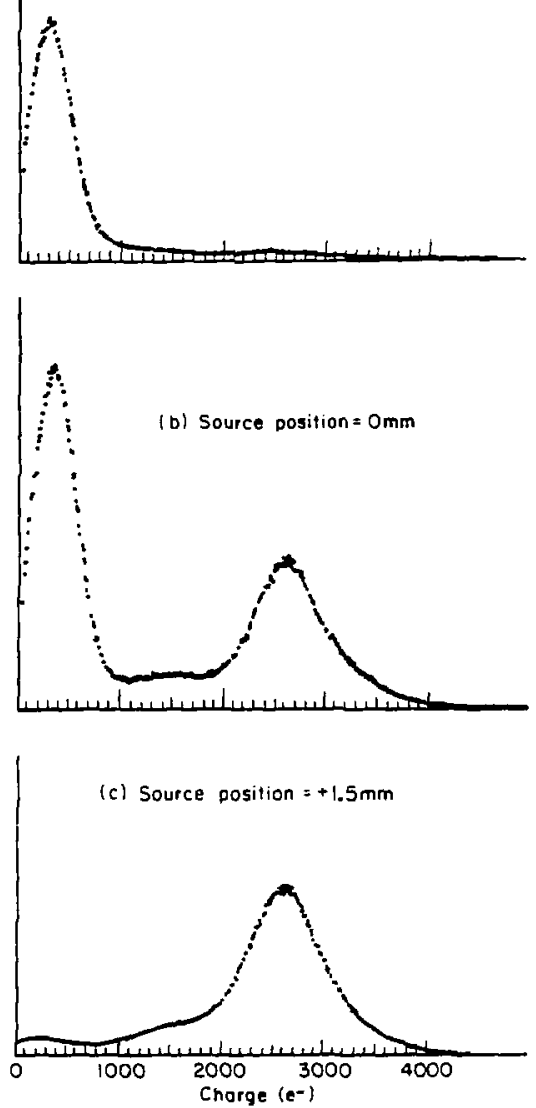

XELBSII-40B7

Figure 5: Pulse height spectra for photodiode $B$ of Figure 4, gated by coincidences between two $>400 \mathrm{keV}$ PMT pulses. The $3 \mathrm{~mm}$ wide upper BGO crystal and the $1.2 \mathrm{~mm}$ diam ${ }^{22 \mathrm{Ma}}$ source define a narrow bean of annihilation photans.

(a) At a source position of $-1.5 \mathrm{~mm}$ the beam intersects crystal $A$ and the SPD $A$ spectrum consists primarily of noise pulses.

(b) At a source position of $0 \mathrm{~mm}$ the bear intersects both erystals $A$ and $B$.

(c) At source position of $+1.5 \mathrm{~mm}$ the bean intersects crystal 8 and the SPD 8 spectrum consists primarily of 511 keV photopezk pulses. 


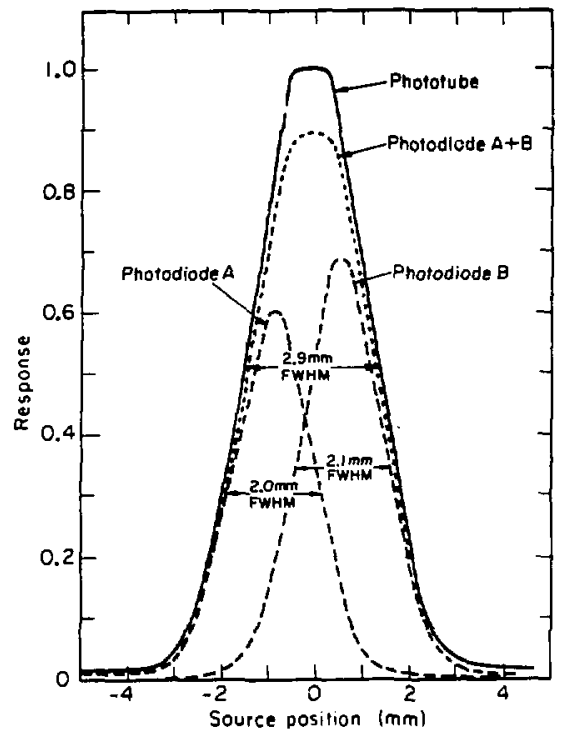

Xoves:-4010

Figure 6: Coincident resoonse function as a line source of $22 \mathrm{Na}$ is moved between the opposing crystals shown in Figure 4 . Phatotube curve is response for two PHTs in coincidence. Photodiode. A and Photodiode $B$ curves are responses when the respective photodiode is in colncidence with both phototubes. Photodiode $A+B$ curve is the sum of Photodiode $A$ and Photodiode $B$ curves.

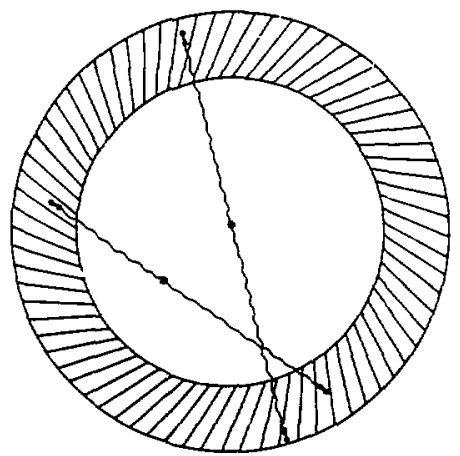

Inisidion

Figure 7: Schene for rotating all crystals of a stationary positron detector ring so that depthof-interaction information can be used to provide continuous linear sampling.
Fortunately, several manufacturers have developed the technology for producing position-sensitive SPDS. In these SPDs, leads are provided to each side of the $P$ or $N$ layer and the resistivity of that layer divides the signal according to the center of intensity of the incident light. Note that for $B G O$ crystais of the shape shown in Figure 1, a two-segnent SPO does not produce signals that are proportional to the position of interaction. Our calculations and experimental simulations using two PMTs indicate that the photons exiting the crystal have d spat tally diffuse component and a sharper component corresponding to the $+45^{\circ}$ total internal reflection escape cone. For interactions over most of the crystal. the esiape cone falls only on one PHT and (except for a narrom region between the PMTs) the resulting signals are vary insensitive to position.

\subsection{Time-uf-Flight positron tomagraphy}

$\mathrm{Baf}_{2}$ is the material of choice for time-of-flight positron tomography 32 , but the spatial resolution is presently limited by the size of high-quality PMTs necessary for sub-nanosecond timing. A fast PHT with d UV window could be coupled to groups of small Baf? crystals to detect the sub-nanosecand emission at 220 $\mathrm{nm}$, and UV sensitive SPOS could be coupled individually to detect the slower 630 ns component at $300 \mathrm{~mm}$.

\subsection{Use of forward Compton scatters}

Detector systems that reject multiple detector interactions do not suffer from a loss in resolution due to Compton scattering in the detectors. However, by increasing the complexity of the event tringer, it 15 possible to include forward Compton events and so increase the detection efficiency without degrading the spatid resolution.

Our Monte iarlo computer code was used to ralculate the probability for one and two crystal photopeak events for a linear array of $3 \mathrm{~mm} \times 10 \mathrm{~mm} \times 30 \mathrm{~mm}$ deep BGO crystals (Table 3). Whenever two crystals are involved. and one has <i70 kev eriergy deposition, it is almost diways the crystal of first interaction. By including such events, the calculdied photopeak eff $i$ clency is increased from 598 to $66 \%$ with little loss in spatial resolution.

\section{Conclusions}

Spatial resolution in positron emission tomography can approach $2 \mathrm{~mm}$ FHHM by using small BGO crystals individually coupled to cooled 51 licon photodiodes (SPDS) for crystal identification and coupled to a comnon phototube for coincident timing information. When $3 \mathrm{~mm} \times 3 \mathrm{~mm} \times 3 \mathrm{~mm} 860$ crystal is coupled on $1 y$ to a SPD at $-150^{\circ} \mathrm{C}$, the 511 kev photopeak resolution is $8.7 \%$ FWHM. TwO $3 \mathrm{~mm} \times 3 \mathrm{~mm} \times 15 \mathrm{~mm}$ BGO crystals coupled to a common PMT can be readily ident ified at $-76^{\circ} \mathrm{C}$ by SPDS, even though the $511 \mathrm{keV}$ photopeak resolution has been degraded to $30 \pi$ FHHM by the higher temperature, light losses in the longer crystals, and the sharing of irght with the PMT. The resulting detector pair resolution of $2 \mathrm{~mm}$ FWHM demonstrates the potential for a new class of ultra-high resolution positron emission tomographs.

\section{Acknow iedgements}

We thank T. Vuletich, G. Chido, and T. Drtiz for technical assistance, $N$. Servies and $A$. Kurahashi of Hamanatsu Corp. for providing silicon photodiodes, and T. Budinger, J. Cahoon, F. Goulding, D. Groom, E. 
Table 3. Probability of 511 kel photopeak events involying 1 or 2 crystais in a linear array of $3 \mathrm{~mm} \times 10 \mathrm{~mm} \times 30 \mathrm{~mm}$ deep 860 crystals a

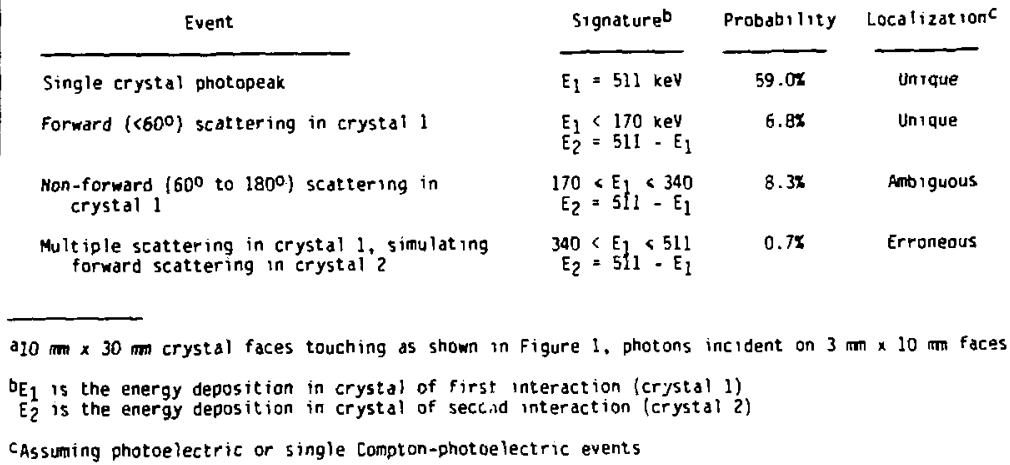

Haller, R, Huesman, and D. Landis for helpful discussions. This work was supported 1 part by the Director, Office of Energy Research, 0.ifice of Health and Environmental Research of the U.S. Department of Energy, under Contract No, OE-ACO3-76SF00098, and in part by the National Institutes of Hedith. National Heart, Lung, and Blood Institute under grant NO. POl HL25840.

\section{REFERENCES}

I. Budinger TF, Derenzo SE, and Huesman RH: Instrument ation for positron emission tomography. Annals of Neurology. 1984 (in press)

2. Derenzo, SE: Precision measurement of annithilation point spread distributions for medically important positron enitters, In: Positron Anninilation. Hasiguti RR and Fujiward $K$, eds, $p p$ 8Ig-823. The Japan Institute of Metals, Sendai, Japan, 1979

3. Derenzo SE, Budinger TF, Huesman RH, and Cahoon JL: Dynanic Dositron enission tomography in man using snall bismuth germanate crystals. In Positron Annihilation. Coleman PG, Sharma SC, and Diana CM, eds. pP 935-945. North-Holland, New York. 198 ?

4. Colombino P, Fiscells B, Trassi L: Study of positronium in water and ice from 22 to $-144{ }^{\circ} \mathrm{C}$ by annihilation quantum measurements. Huovo Cimento 38: 707-723, 1965

5. Derenzo SE: Monte Carlo calculations of the dacection efficiency of arrays of $\mathrm{NaI}(\mathrm{TI}), 860$. isf. Ge, and plastic detectors for 511 key photons. IEEE Trans Muc I Sci NS-28: No 1. 131-136. 1981

6. MeIntyre JA: Plastic scintillation detectors for high resolution emission computed tamography. J Comput Assist Tomogr 4: 351-360, 1980
7. Derenzo SE, Budinger TF, and Vuletich T: High resolution positron emission tomography using narrow bismuth germanate crystals and individual photosensors. IEEE Trans Nucl SCi N5-30: No I. $665-670,1983$

8. Ricer A, Hoffman E. Phelps $K$, et al: Investigation of a technique for providing a pseudocontinuous detector ring for positron tomography, IEEE Trans Nucl Sci N5-29: No I, 452-456, 1982

9. Burnhan $C$, Bradshaw $J$, Kaufman 0 , et al: One dimensional scintillation cameras for positron ECT ring detectors. IEEE Trans Nucl Sc $i$ NS-28: No $1,109-113,1981$

10. Burnham C, Bradshaw J, Kaufman D, et al: Application of a one dimensional scintillat ion camera in a positron tomographic ring detector. IEEE Trans Nuel Sci NS-29: No 1, 461-464, 1982

11. Burnham [, Bradshaw J, Kaufman D, et al: A positron tomograph employing a one Jimension BGO scintillation camera. IEEE Trans Nucl Sci NS-30: No $1,661-664,1983$

12. Muehllehner G, Colsher JG, and Lewitt RM: A hexagonal bar positron camera: problems and solutions. IEEE Trans Nuel SeI NS-30: No 1, 652660,1983

13. Burnhan CA, Bradshaw J, Kaufman 0 , et sl: A stationary positron emission ring tomograph using $B G O$ detectar and and lag readout. IEEE Trans Mucl Sci NS-31, 1984 (in press)

14. Murayama $H$, Nohara $N$, Tanaka $E$, et al: A quad $B G O$ detector and 1 ts timing and positioning discrimination for positron computed tomography. Mucl Instr Meth 192: 501-511, 1982

15. Thompson CJ: Presented at the IEEE Nuclear Science Symposium, San Francisco, CA, October $19-21.1983$ 
16. Eriksson L: A high resolution positron canerd. Proceedings of the VII Nobel Conference: "The Wetabolism of the Human Brain Studied with Positron Emission Tomography", Karolinska Inst 1tute. Stackholm, May 17-20, 1983

17. Hong WH, Mullani NA, and Wardworth G: CharaCteristics of small barium fluoride $\left(\mathrm{BaF}_{2}\right)$ scintillator for high intrinsic resolution timeof-flight pasitron tomography. IEEE Trans Nuc! Sci NS-31, 1984 (in press)

18. Charpak 6: The localization of the position of light impact on the photocathode of a photomultiplier. Nure? lastr Meth 48: 151-153, 1967

19. Charpak 6: Retardation effects due to the localized apphication of electric fields on the photocathode of a photomultiplier. Nucl Instr Meth 51: 125-128, 1967

20. Boutot JP and Pretri G: Photomultiplier controi by a clamping cross-bar grid. IEEE Irans Nucl SC] NS-19: No 3, 101-106, 1972

21. Yamashita $Y$ Uchida $H$, Yanashid $T$ and Hayashy $T$ : Recent development in detectors for high spatial resolution positron CT. IEEE Irans NuCl SCI NS-31, 1984 (In press)

22. Barton J8, Hoffman EJ, I wanczyk JS, et al: A high-resolution detection system for positron tomography, IEEE Irans NuCl SCI NS-30: No 1 . $671-675,[983$

23. Derenzo SE and Riles J: Monte Carlo calculations of the optical coupling between bismuth germanate crystals and photomultiplier tubes. IEEE Trans NuC I SCI NS-29: No 1, 191-195, 1982

24. Moss TS, Burrell GJ, and Ellis B: Semicanductor Opto-electronics. John Wiley. New York, 1973, pp 184-135

25. Imanczyk JS, Bartan JB, Dabrowsk I AJ, et al: A novel radiation detector consisting of an $\mathrm{Hgl}$ ? photodetector coupled to a scintiliator. IEEE Trans Nucl SCI NS-30: No 1, 363-367, 1983

26. iwanczyk J, Dabrowsk, A, Markakis J, et al: Large area mercuric lodide photodetectors. IEEE Trans NuC I SCl NS-31, 1984 (in press)

27. Derenzo SE: Gamma-ray spectroscopy using sinall. cooled bismuth germanate scintillators and sil: icon photodrodes. Hucl Instr Meth. (in press), 1983

28. Technical data supplied by Hanamatsu TV Co., Ltd., Hamamat su, Japan

29. 8irks J8: The Theory and Practice of Scint illidtion Count ing. Pergamon press, Oxford, England, 1964. Dp 473-474

30. W. Van Seiver, personal communication, 1983

31. Gariod R, Allemand R, Cormoreche E, et al: The "LETI" positron tomograph architecture and time of flight improvetnents. Proceedings of the Workshop on time-of-Flight Tomography, op 25-29. Hashington University. 5t. Lou's M0. May, 1982. (IEEE Cat. No. 82CH179]-3)
32. Laval M, Moszynski M, Allentand fluoride: inorganic scintillator for subnanosecond timing. Nucl Instr Meth 206: 169-176, 1983

Reference to a campany or product name does not imply approval or recomendation of the product by the University of California or the U.S. Department of Energy to the exclusion of others that may be suitable. 
This report was done with support from the Dipartmenl of Energy. Any conclusions or opinions expressed in this report represent solely those of the authar(s) and not necessarily those of The Regents of the Universily of California, the Luswicnce Berkeley Laboratory of the Department of Energy.

Reference 10 a company or product name does not imply approval or recommendation of the product by the University of California or the U.S. Department of Energy to the exclusion of others that may be suitable. 